\title{
Validity and reliability of State-Trait Anxiety Inventory in Danish women aged 45 years and older with abnormal cervical screening results
}

\author{
L. W. Gustafson ${ }^{1,2^{*+}}$, P. Gabel ${ }^{1 \dagger}$, A. Hammer ${ }^{2,3}$, H. H. Lauridsen ${ }^{4}$, L. K. Petersen ${ }^{5}$, B. Andersen ${ }^{1,2}$, P. Bor ${ }^{2,6}$ and
} M. B. Larsen ${ }^{1}$

\begin{abstract}
Background: State Trait Anxiety Inventory (STAI) scale was developed in the 1980's and has been widely used both in clinical settings and in research. However the Danish version of STAI has not been validated. The aim of this study was to assess the validity and reliability of STAI - state anxiety scale in Danish women aged 45 years and older with abnormal cervical cancer screening results.

Methods: Women $\geq 45$ years referred with an abnormal cervical cytology and healthy volunteers $(n=12)$ underwent cognitive interview after completing STAI. Further, STAI was sent out in an electronic questionnaire to women $(n=109)$ seen at the gynecological department with abnormal cervical cancer screening test during 2018. Validity and reliability of STAI was evaluated according to the Consensus-based Standards for the selection of health Measurement Instruments (COSMIN) checklist by examining internal consistency, test-retest reliability, measurement error, floor and ceiling, construct validity and content validity.
\end{abstract}

Results: In the cognitive interviews the content validity was evaluated to be very good. The internal consistency of the scale was excellent with Cronbach's $a=0.93$. Test-retest reliability was good with an intra-class correlation coefficient of 0.80 and the systematic difference between test-retest results was negligible. The construct validity was good.

Conclusion: To our best knowledge, this is the first validation study of the Danish translation of STAl-state anxiety scale. This version of STAI demonstrates an acceptable reliability and validity when used in a gynecological setting.

Keywords: State trait anxiety inventory, Anxiety, Questionnaire, Abnormal cervical screening test, Validation and reliability

\footnotetext{
* Correspondence: line.winther@skejby.rm.dk

Gustafson LW and Gabel P are co-first authors.

${ }^{\dagger}$ L. W. Gustafson and P. Gabel contributed equally to this work.

'Department of Public Health Programmes, Randers Regional Hospital,

Randers, Denmark

${ }^{2}$ Department of Clinical Medicine, Aarhus University, Aarhus, Denmark

Full list of author information is available at the end of the article
}

\section{Background}

Cervical cancer is the fourth most common cancer worldwide with 569,847 new cases and 311,365 deaths in 2018 [1]. Cervical cancer may be prevented by Human Papillomavirus (HPV) vaccination or screening [2]. Screening allows for detection and treatment of cervical precancerous lesion, thereby reducing cervical cancer incidence and mortality. In case of an abnormal

C C The Author(s). 2020 Open Access This article is licensed under a Creative Commons Attribution 4.0 International License, which permits use, sharing, adaptation, distribution and reproduction in any medium or format, as long as you give appropriate credit to the original author(s) and the source, provide a link to the Creative Commons licence, and indicate if changes were made. The images or other third party material in this article are included in the article's Creative Commons licence, unless indicated otherwise in a credit line to the material. If material is not included in the article's Creative Commons licence and your intended use is not permitted by statutory regulation or exceeds the permitted use, you will need to obtain permission directly from the copyright holder. To view a copy of this licence, visit http://creativecommons.org/licenses/by/4.0/ The Creative Commons Public Domain Dedication waiver (http://creativecommons.org/publicdomain/zero/1.0/) applies to the data made available in this article, unless otherwise stated in a credit line to the data. 
screening test, a woman is referred to a gynecologist for colposcopy. Using a colposcope the cervix can be visualized and evaluated, allowing for targeted biopsies of visible lesions. A cone biopsy may subsequently be performed during the diagnostic workup or for treatment of histologically verified lesions. The colposcopic examination carries a low risk of physical harm, such as bleeding and infection, but several studies have demonstrated that an abnormal screening test result and referral for colposcopy may be associated with increased levels of anxiety and discomfort [3-8].

Anxiety among patients in a gynecological setting has been measured using different scales such as the Psychological Consequences Questionnaire, Hospital Anxiety and Depression Scale, the Montgomery-Åsberg Depression Rating Scale, and different versions of State-Trait Anxiety Inventory (STAI) $[5,6,9]$. STAI has the advantage of measuring both trait anxiety, which is considered stable over time, and state anxiety, which is affected by stressful situations such as receiving an abnormal screening result $[10,11]$.

However, to our best knowledge, the Danish version of STAI has not been validated, neither in a gynecological setting nor in any other Danish setting. In this study we focused on the state scale of STAI as this scale has been used to measure anxiety over time and in relation to a given event. We aimed to test validity and reliability of the STAI - state anxiety scale among Danish women aged 45 years and older with abnormal cervical cancer screening results by examining internal consistency, testretest reliability, measurement error, floor and ceiling, construct validity and content validity.

\section{Methods}

\section{Setting}

The study was conducted at the Department of Obstetrics and Gynecology, Randers Regional Hospital, which is located in Central Denmark Region, one of five Danish regions governing primary and secondary health care services. In Denmark, all citizens have access to free health care due to a tax-financed health care system [12]. Danes are required to communicate with health authorities and hospitals through secure digital mail which less than $10 \%$ of the Danish citizens are exempt from [13]. This digital mail allows for communication of digital questionnaires directly to Danish citizens.

\section{Study design}

A two-step validation study of the Danish version of STAI - state anxiety scale was conducted to evaluate how well the Danish translation of the scale performed in a gynecological outpatient clinic. Cognitive interviews were conducted to test content validity and a questionnaire study was conducted to test reliability, floor and ceiling effect, and construct validity.

\section{Cognitive interviews Study population}

We conducted individual interviews with women aged 45 years and older with and without an abnormal cervical screening test. Women were eligible for interview if they were referred to the Department of Obstetrics and Gynecology, Randers Regional Hospital or to a private gynecologist in Randers due to an abnormal screening test. Women were considered ineligible if they were unable to speak and understand Danish. A convenience sample of women without an abnormal screening result was also interviewed.

\section{Data collection}

Individual interviews were conducted from 4th December 2018 to 13th December 2018. Eligible women were asked by the medical staff at the gynecological department or at the private gynecologist if they were interested in participating. Patients agreeing to participate were instructed to fill out the questionnaire in a quiet room. Subsequently, they were interviewed by author LWG who is trained in qualitative research. A semi-structured interview guide was designed to cover the women's opinion in terms of comprehensiveness, comprehensibility, and relevance of the questionnaire items. Each interview was documented by taking notes during the interview. Interviews were conducted until data saturation was reached.

\section{Analyses}

Open-ended questions were asked about the following categories: understanding of the answer categories of the scales, time-consumption, layout of the questionnaire, the comprehensibility and relevance of the questions, and how they interpreted the questions. An inductive analysis was performed to make more general conclusions on the respondents' statements.

\section{Questionnaire study \\ Study population}

The questionnaire was sent to women 45 years or older who had been referred to the Department of Obstetrics and Gynecology, Randers Regional Hospital from 1 January 2018-7 December 2018 due to an abnormal screening result. Women exempted from the digital mail were excluded (Fig. 1).

\section{Data collection}

The questionnaire consisted of the Danish translation of STAI - state anxiety scale along with Short Form 12 Health Survey (SF-12) which was used for hypothesis 


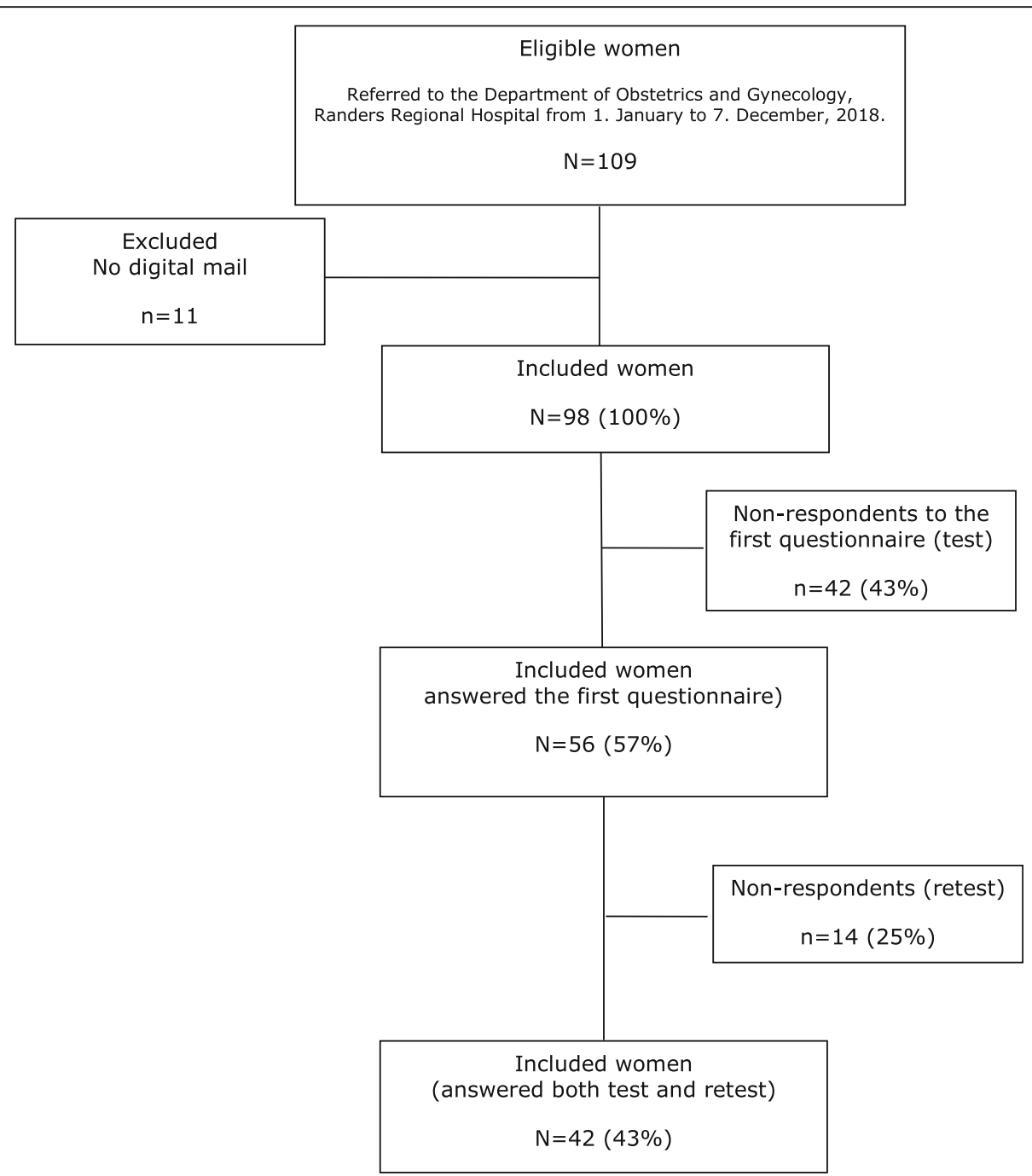

Fig. 1 Flow chart of women included in the quantitative validation of STAl-state anxiety scale

testing to assess construct validity of STAI - state anxiety scale.

It was set up in REDCap ${ }^{\text {TM }}$ (Research Electronic Data Capture) hosted at Aarhus University. REDCap is a secure, web-based software platform designed to support data capture for research studies [14, 15]. All questions in the questionnaire were mandatory to ensure no missing values.

The questionnaire was sent electronically through the digital mail to eligible women on 3rd January 2019 along with information on the validation process of the questionnaire, including the reason for test-retest, and an individual link to the electronic questionnaire. One week later a reminder was sent to non-responders. Fourteen days after the first questionnaire was answered the same questionnaire was sent for a test-retest and 1 week later a reminder was sent to non-responders in the retest.

\section{Questionnaires}

STAI - state anxiety scale The Danish version of STAI - state anxiety scale was provided by the copyright owner (Mind Garden, Inc., USA) with no information on the translation process or validation data.

STAI - state anxiety scale consists of 20 items with response options based on a self-reported 4-point Likert scale ("Not at all", "Somewhat", "Moderately so" and "Very much so"). The state anxiety score ranges from a minimum of 20 to a maximum of 80 . A low score indicates no or little anxiety while a higher score indicates a higher level of anxiety. All items of the state anxiety scale were found to belong to one uni-dimensional scale [16].

Norm data for STAI - state anxiety scale for working adults based on a total of 1838 employees of the Federal Aviation Administration (1387 males; 451 females) was 
available from the STAI Manual. Although most were non-Hispanic white, the sample was heterogeneous with regard to educational level and age. The mean score for working females aged 40-49 was 36.03 (SD 11.07) and 32.20 (SD 8.67) for working females aged $50-69$ years [11].

Short form 12 health survey (SF-12) SF-12 is a healthrelated quality of life questionnaire consisting of 12 items divided into two sub-scales of physical and mental health. The total score ranges from 0 to 100 , where zero indicates the lowest level of health-related quality of life and 100 indicates the highest level of health-related quality of life.

\section{Analyses}

Validity and reliability of the scale was evaluated according to the COSMIN (COnsensus based Standards for the selection of health status Measurement INstruments) checklist [17]. All statistical analyses were conducted on the initial test results and only measurement error and test-retest reliability included results from the retest.

\section{Reliability}

Internal consistency Internal consistency was assessed by Cronbach's $\alpha$ which was presented for the scale as a whole with 95\% confidence interval (CI). Cronbach's $\alpha$ values between $0.7-0.9$ were regarded as acceptable [18].

Test-retest reliability The test-retest reliability was assessed by calculating the intra-class correlation coefficient (ICC) using the two-way mixed-effect model with interaction for the absolute agreement between single scores [19]. ICC between 0.5-0.75 indicates moderate reliability, $\leq 0.75-0.9$ indicates good reliability and greater than 0.9 indicates excellent reliability [20].

Measurement error Measurement error was presented as the limits of agreement with the test-retest score, and differences were plotted against the average test-retest scores in a Bland-Altman plot [21]. Furthermore, we calculated the smallest detectable change (SDC) defined as $1.96 \times \mathrm{SD}_{\text {difference. }}$ This equals the limits of agreement without the systematic error [22].

Floor and ceiling effect Floor and ceiling effects were illustrated in histograms for each item and the total score, and assessed as the number of participants achieving the highest or lowest possible score. If more than $15 \%$ scored at either end of the scale, we defined this as a floor/ceiling effect [23].
Construct validity Construct validity was assessed by performing hypothesis testing against SF-12 scores in the questionnaire using a Spearman's rank correlation. Correlation coefficients above $>0.5$ indicated a strong correlation, $0.3-0.5$ indicated a moderate correlation and $<0.3$ indicated a weak correlation [24]. Further, hypothesis testing was based on the mean score for American working females aged 50-69 years provided in the STAI state manual [11] using the Student's t-test.

The first hypothesis was that there would be a strong correlation $(\geq 0.5)$ between anxiety measured by the STAI-state anxiety scale and mental health measured by SF-12, as the two scales measure similar constructs. Since higher STAI-state anxiety scores indicate higher anxiety and lower SF-12 scores indicate poor mental health, the association was expected to be negative. Further, it was hypothesized that there would be a moderate (0.3-0.5) and negative correlation between high levels of anxiety and poor physical health as high levels of anxiety do not necessarily affect one's physical health. The third hypothesis was that the mean scores reported in the STAI manual (women 50-69 years) would not be statistically significant different from the Danish STAI-state anxiety scale mean scores $(p>0.05)$.

All statistical analyses were conducted in Stata/SE 15 (StataCorp. 2017. Stata Statistical Software: Release 15. College Station, TX: StataCorp LLC).

\section{Study approvals}

According to EU's General Data Protection Regulation (article 30), the project was listed at the record of processing activities for research projects in Central Denmark Region (J. No. 1-16-02-528-18). The present study has been presented to the Central Denmark Region Committees on Health Research Ethics. The Committee decided that according to the Danish Act on Research Ethics Review of Health Research Projects (Act number 111/2017), this study should not be notified to the Committees (j.no:1-10-72-4-17).

\section{Results}

\section{Cognitive interviews}

Seven women with abnormal cervical screening results (mean age 63.9 years (SD 7.99)) and five women without abnormal cervical screening results (mean age 51.8 years (SD 8.98)) were included for individual interviews.

\section{Content validity}

The 12 women both with and without abnormal cervical screening results reported that the STAI- state anxiety scale was relevant and easy to interpret. They liked that it was short and yet comprehensive. They found the response options to be appropriate and the wording was easy to understand. They did not suggest adding 
questions or changing the wording of the existing questions. From the individual interviews, content validity was evaluated to be very good.

\section{Questionnaire study Participants}

A total of 109 women were eligible for validation of the reliability and validity of STAI-state anxiety scale. Of these, 98 women had electronic mail and were invited to participate (mean age 58.1 years (SD 9.12)). A total of 56 women completed the first questionnaire (57\%) (mean age 59.3 years (SD 9.38)), and a total of 42 women completed both test and retest questionnaires (43\%) (mean age 57.9 (SD 8.22)) (Fig. 1).

The overall mean score of STAI - state anxiety scale was 32.6 (SD 10.4). The mean score for women aged 45-49 years was 32.6 (SD 11.1), for women aged 50-69 years it was 32.3 (SD 10.6) and for women 70 years or older it was 34.4 (SD 10.41).

\section{Reliability}

Internal consistency The internal consistency of the scale was excellent (Cronbach's $\alpha=0.93$; 95\% CI: 0.91; 0.97).

Test-retest reliability The test-retest reliability was good with an ICC of 0.80 (95\% CI: 0.66; 0.89).
Measurement error The systematic difference between test and retest results was 0.40 points $(95 \% \mathrm{CI}:-0.88$; 2.69 ), and the lower and upper limits of agreement was -13.98 and 14.79 , respectively (Fig. 2). The SDC was 14.4 points which means that change outside 14.4 points can be considered a true change [18].

Floor and ceiling effect In most items, all possible answers had been used, with a tendency towards lower scores in all items (Fig. 3). Total score ranged from 20 to 60 out of 80 possible, with lower scores being most common (Fig. 4). Five (8.9\%) participants had a total score of 20 and 0 had a total score of 80 revealing no floor or ceiling effects.

\section{Construct validity \\ Hypothesis testing}

Correlation between the STAI state anxiety scale and SF-12 physical health was negative and moderate (0.3082 , 95\% CI: $-0.5610 ;-0.0555)$ and for SF-12 mental health negative and strong $(-0.6752,95 \% \mathrm{CI}:-0.8043$; - 0.5461) both confirming our hypotheses (Table 1).

There was a difference of 0.14 (95\% CI: -2.82 ; $3.10)$ in the mean score for STAI state anxiety scale ranging from 20 to 80 between the STAI manual and our findings confirming our hypothesis of no difference (Table 1).

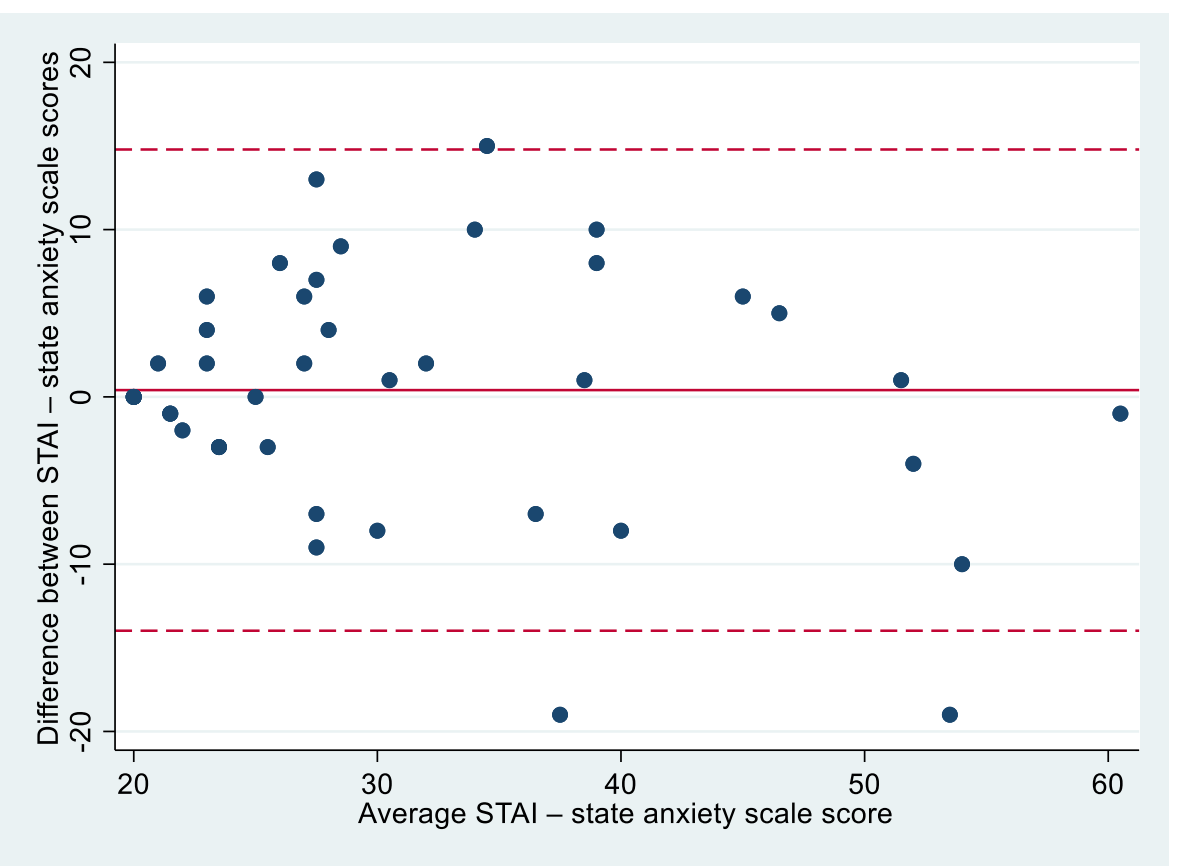

Note: $\mathrm{n}=42$

Fig. 2 Bland-Altman plot of test-retest score differences against mean test-retest scores with $95 \%$ limits of agreement $(n=42)$ 

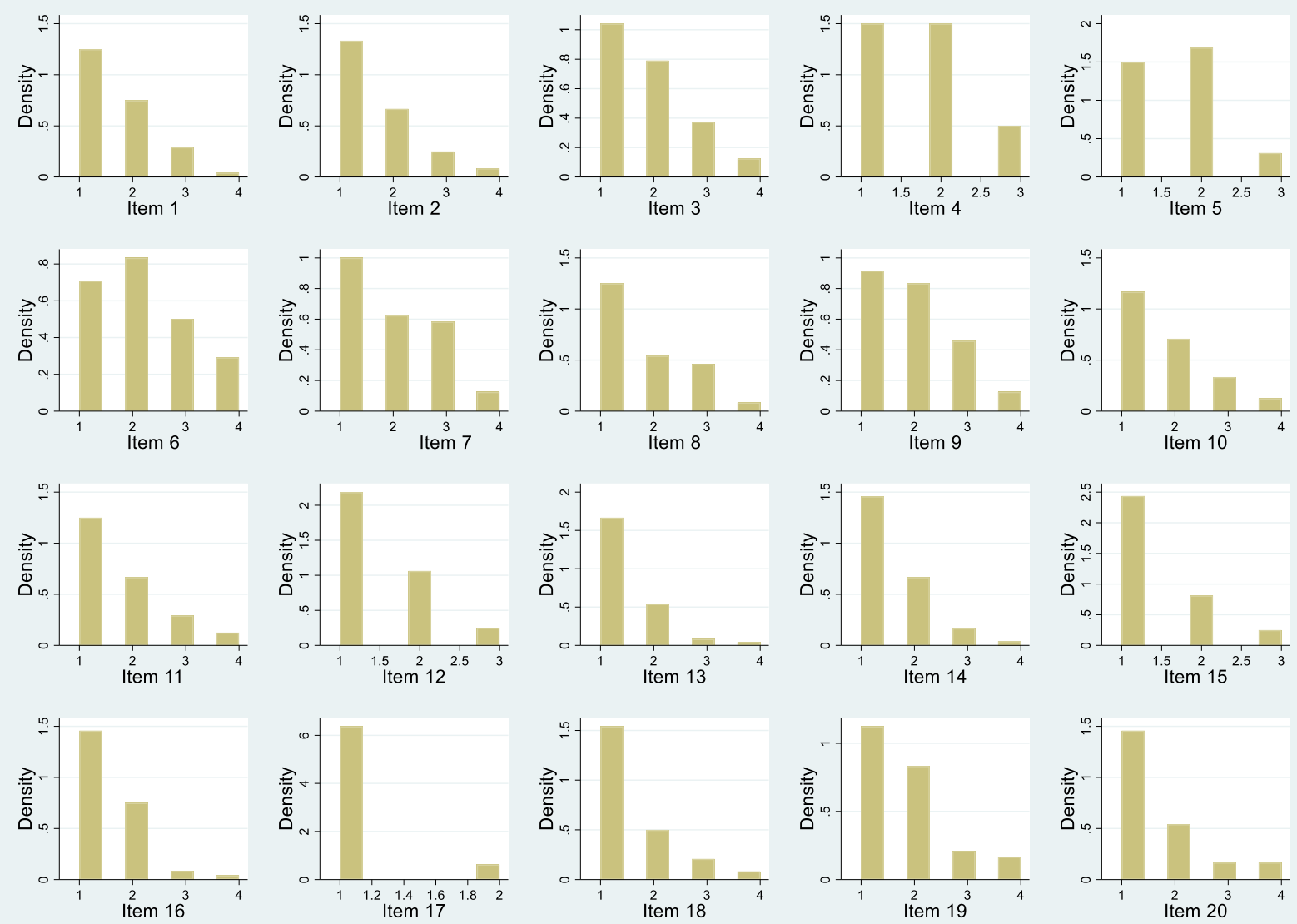

Note: $x$-axis is the scale score for each item ranging from 1-4

Fig. 3 Histograms of item score for each item in the STAl-state anxiety scale $(n=56)$

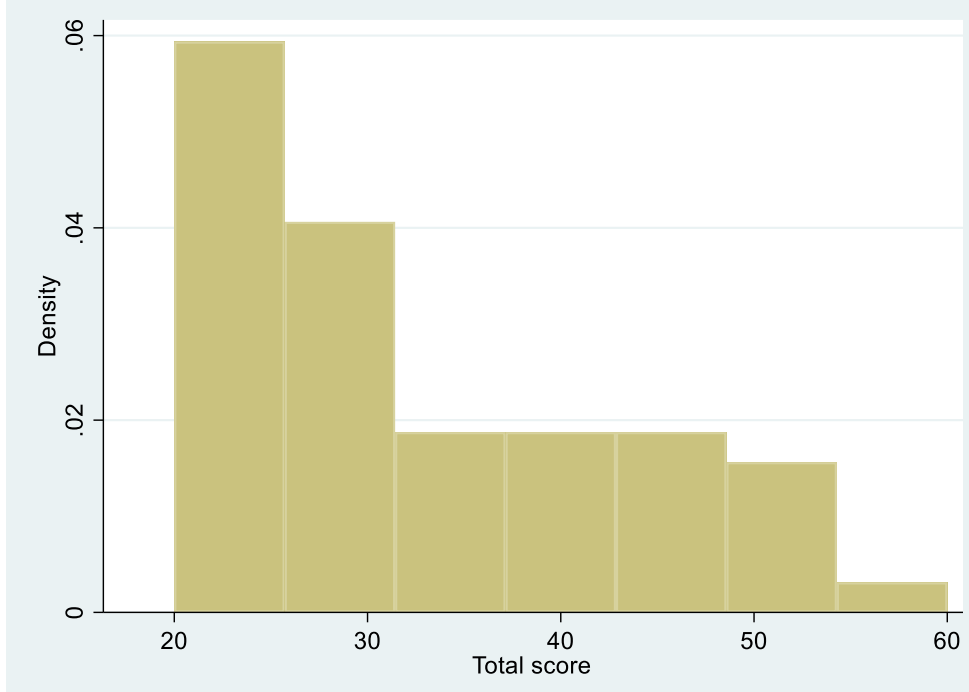

Note: $\mathrm{x}$-axis is the total scale score for each item ranging from $20-80$

Fig. 4 Histogram of total score of the STAl-state anxiety scale $(n=56)$ 
Table 1 Hypothesis testing against SF-12 mental and psychical health and mean scores in the STAI manual

\begin{tabular}{|c|c|c|}
\hline Hypothesis testing & Correlation & Difference (50-69 yrs) \\
\hline $\begin{array}{l}\text { SF-12 mental health scale versus } \\
\text { STAl - state anxiety scale* }\end{array}$ & $\begin{array}{l}\text { Spearman's rho }=-0.6752 \\
95 \% \mathrm{Cl}(-0.8043 ;-0.5461)\end{array}$ & \\
\hline $\begin{array}{l}\text { SF-12 physical health scale versus } \\
\text { STAI state anxiety scale** }\end{array}$ & $\begin{array}{l}\text { Spearman's rho }=-0.3082 \\
95 \% \mathrm{Cl}(-0.5610 ;-0.0555)\end{array}$ & \\
\hline $\begin{array}{l}\text { STAl state anxiety scale (manual) versus } \\
\text { STAl state anxiety scale***}\end{array}$ & & $\begin{array}{l}\text { Difference }=0.14 \\
95 \% \mathrm{Cl}(-2.82 ; 3.10)\end{array}$ \\
\hline
\end{tabular}

\section{Discussion}

\section{Main findings}

To our best knowledge, this is the first validation study of the Danish translation of STAI-state anxiety scale. The results indicated that the scale holds acceptable validity in a population of Danish women older than 45 years in a gynecological setting. Content validity, internal consistency, test-retest reliability and construct validity was good. The mean score resembled norm data for working females, indicating that women with an abnormal cervical screening test within the last year are fairly unaffected by anxiety and mimics the background population.

\section{Strengths and limitations}

This study benefitted from the two-step validation procedure, including both interviews and questionnaire. Even though Mind Garden, Inc., USA, provides no information on the translation process or validation data on the Danish version of the STAI-state anxiety scale, the individual interviews confirmed that Danish women with and without an abnormal screening test found the scale comprehensible and relevant. This may indicate that both the original concept of STAI-state anxiety and the Danish translation is accepted among Danish women.

The main limitation of the study was the relatively low number of women included in the questionnaire study. However, we included all women referred to the Department of Obstetrics and Gynecology, Randers Regional Hospital from 1 January 2018-7 December 2018 who had an abnormal screening test. Due to the relatively small study population we were unable to conduct a factor analysis to confirm that the scale was unidimensional, and we therefore had to rely on the validation of the original scale.

Furthermore, we cannot rule out selection bias, as only $57 \%$ responded $(56 / 98)$ in the initial questionnaire, and $43 \%(42 / 98)$ in the retest, and because we only included women with digital secure mail. We were unable to determine the magnitude of this potential bias, as we only had information on age of non-respondents and because we have no information on women exempt from digital mail. However, respondents had similar age distribution as those who did not respond. Still, the respondents may be a selected group in terms of health status, socioeconomic status, and other unknown factors. This may partly explain that no one scores at the highest end of the scale if those most affected by anxiety did not participate in this study, which is always a dilemma in research. Further, the women were recruited based on a visit to a gynecologist within the past year which may further explain that the mean score resembled the mean score from norm data.

Our results showed a relatively high SDC for several reasons. Recruiting women at the day of their gynecology appointment and letting them fill out the questionnaire on that day might have yielded higher scores which could not be reproduced in a retest after 2 weeks, because STAI - state anxiety scale measures transitory anxiety. Furthermore, we did not include a stability anchor to exclude those who had changed over the 2 weeks between test and retest, and this probably resulted in an inflated measurement error. Consequently, our SDC is probably too high and therefore has to be used and interpreted with caution.

Another limitation was that the digital questionnaire was set up not to allow missing values which would normally be avoided in validation studies. However, since item formulation, relevance and acceptability were already tested in the interviews, it was decided to help the respondents not to miss any questions due to the digital setup where it may be difficult to visualize if all answers had been marked.

\section{Discussion of results and comparison to other studies}

Even though STAI-state anxiety scale has been widely used for decades, we were only able to find few other validation studies, including a Greek [25], Japanese [26], Taiwan [27] and a Malaysian study [28]. The majority of these studies was published before the COSMIN checklist and varies widely in design and methods.

None of the previous studies conducted confirmatory factor analysis to confirm uni-dimensionality of the state anxiety scale. Thus, factor analysis is only reported in the STAI manual. In previous studies, a high internal 
consistency was found (0.87-0.93) [25-28], which is in line with our findings.

Our results are in line with a Swedish cohort study [5], where they measured STAI state anxiety in women referred for colposcopy. They found a mean STAI state anxiety score at the first colposcopy visit to be 42.7 , declining to 35.0 after 2 years follow-up. A reference group with healthy women participating in the cervical cancer screening program was found to have a mean state anxiety score at 34.8. Similar results were seen in the study from J. Byrom et al., in which women had a mean score of 45.94 before colposcopy and 36.916 weeks after colposcopy [3]. In a Finnish study, women referred for colposcopy had a mean score of 34 both at baseline, six and 12 months after referral to colposcopy [4] These numbers are similar to our results and are measured in a comparable target population.

\section{Conclusion}

The Danish version of STAI-state anxiety scale demonstrates an acceptable reliability and validity when used in a gynecological setting. The most important issue for future studies is the considerable measurement error related to the scale. Thus, we recommend using a stability anchor along with the STAI-state anxiety scale.

\section{Abbreviations \\ STAI: State-Trait Anxiety Inventory; COSMIN: Consensus-based Standards for the selection of health Measurement Instruments; HPV: Human Papillomavirus; SF-12: Short form 12; Cl: Confidence interval; SD: Standard deviation; REDCAP: Research Electronic Data Capture; ICC: intra-class correlation coefficient; SDC: Smallest Detectable Change}

\section{Acknowledgements}

We thank Secretary Marianne R. Pedersen for sending the electronic questionnaire out.

\section{Authors' contributions}

LWG, MBL, PB, LKP, BA and AH designed the study. LWG conducted the study. LWG, PG and MBL analyzed the data with contribution from HHL. LWG wrote the first draft and MBL, PG, HHL, PB, AH, LKP and BA revised the paper and approved the final version of the manuscript.

\section{Funding}

Funding for the trial was obtained from following organizations: Health Research Fund of Central Denmark Region.

Department of Public Health Programmes.

Dagmar Marshall Foundation.

Einar Willumsens Foundation.

The funder had no role in the study design, data collection, data

interpretation, or writing of the manuscript.

\section{Availability of data and materials}

The dataset generated and analyzed in this study are not available for the public due to Danish legislation. Data are available on request for researchers who meet the criteria for access to patient's confidential data.

\section{Ethics approval and consent to participate}

According to EU's General Data Protection Regulation (article 30), the project was listed at the record of processing activities for research projects in Central Denmark Region (J. No. 1-16-02-528-18).

The present study has been presented to the Central Denmark Region Committees on Health Research Ethics. The Committee decided that according to the Danish Act on Research Ethics Review of Health Research Projects (Act number 111/2017), this study should not be notified to the Committees (j.no:1-10-72-4-17). Therefor consent was not required for this study and the waiver was approved by the Central Denmark Region

Committees on Health Research Ethics and Department of Gynecology and Obstetrics, Randers Regional Hospital.

\section{Consent for publication}

Not applicable.

\section{Competing interests}

The authors declare that they have no competing interests.

\section{Author details}

'Department of Public Health Programmes, Randers Regional Hospital, Randers, Denmark. ${ }^{2}$ Department of Clinical Medicine, Aarhus University, Aarhus, Denmark. ${ }^{3}$ Department of Obstetrics and Gynecology, Herning Regional Hospital, Herning, Denmark. ${ }^{4}$ Department of Sports Science and Clinical Biomechanics, University of Southern Denmark, Odense, Denmark. ${ }^{5}$ Open Patient Data Explorative Network (OPEN) and Department of Obstetrics and Gynecology, Odense University Hospital, Odense, Denmark. ${ }^{6}$ Department of Obstetrics and Gynecology, Randers Regional Hospital, Randers, Denmark.

Received: 22 January 2020 Accepted: 16 April 2020

Published online: 23 April 2020

\section{References}

1. Ferlay J, Colombet M, Soerjomataram I, Mathers C, Parkin DM, Pineros M, et al. Estimating the global cancer incidence and mortality in 2018: GLOBOCAN sources and methods. Int J Cancer. 2019;144(8):1941-53.

2. The Danish Health Authority: Screening for cervical cancer 2018 (in Danish only). 2018; Available at: https://www.sst.dk/da/sygdom-og-behandling/ screening. Accessed 12 July 2019.

3. Byrom J, Clarke T, Neale J, Dunn PD, Hughes GM, Redman CW, et al. Can pre-colposcopy sessions reduce anxiety at the time of colposcopy? A prospective randomised study. J Obstet Gynaecol. 2002;22(4):415-20.

4. Heinonen A, Tapper AM, Leminen A, Sintonen H, Roine RP. Health-related quality of life and perception of anxiety in women with abnormal cervical cytology referred for colposcopy: an observational study. Eur J Obstet Gynecol Reprod Biol. 2013;169(2):387-91.

5. Hellsten C, Sjostrom K, Lindqvist PG. A prospective Swedish cohort study on psychosocial factors influencing anxiety in women referred for colposcopy. BJOG. 2007;114(1):32-8.

6. Korfage IJ, van Ballegooijen M, Huveneers H, Essink-Bot ML. Anxiety and borderline PAP smear results. Eur J Cancer. 2010;46(1):134-41.

7. Freeman-Wang T, Walker P, Linehan J, Coffey C, Glasser B, Sherr L. Anxiety levels in women attending colposcopy clinics for treatment for cervical intraepithelial neoplasia: a randomised trial of written and video information. BJOG. 2001;108(5):482-4.

8. Chan YM, Lee PW, Ng TY, Ngan HY. Could precolposcopy information and counseling reduce women's anxiety and improve knowledge and compliance to follow-up? Gynecol Oncol. 2004;95(2):341-6.

9. Ketelaars PJW, Buskes MHM, Bosgraaf RP, van Hamont D, Prins JB, Massuger $L F A G$, et al. The effect of video information on anxiety levels in women attending colposcopy: a randomized controlled trial. Acta Oncol. 2017; 56(12):1728-33.

10. Spielberger CD, Gorsuch RL, Lushene RE. Manual for the state-trait anxiety inventory (self-Evaluaton questionnaire); 1970.

11. Spielberger CD, Gorsuch RL, Lushene RE, Vagg PR, Jacobs GA. Manual for the state-trait anxiety scale; 1983.

12. Schmidt M, Schmidt SAJ, Adelborg K, Sundboll J, Laugesen K, Ehrenstein V, et al. The Danish health care system and epidemiological research: from health care contacts to database records. Clin Epidemiol. 2019;11:563-91.

13. Agency for Digitisation. Statistik om Digital Post [in Danish]. Available at: https://digst.dk/it-loesninger/digital-post/om-loesningen/tal-og-statistik-omdigital-post/. Accessed 10 July 2019.

14. Harris PA, Taylor R, Thielke R, Payne J, Gonzalez N, Conde JG. Research electronic data capture (REDCap)--a metadata-driven methodology and workflow process for providing translational research informatics support. J Biomed Inform. 2009;42(2):377-81. 
15. Harris PA, Taylor R, Minor BL, Elliott V, Fernandez M, O'Neal L, et al. The REDCap consortium: Building an international community of software platform partners. J Biomed Inform. 2019;95:103208.

16. Vagg PR, Spielberger CD, O'Hearn TP. Is the state-trait anxiety inventory multidimensional? Personal Individ Differ. 1980;1(3):207-14.

17. Mokkink L, Prinsen C, Patrick D, Alonso J, Bouter $L$, de Vet $H$, et al. COSMIN study design checklist for patient-reported outcome measurement instruments. 2019. Available at: https://www.cosmin.nl/wp-content/uploads/ COSMIN-study-designing-checklist_final.pdf. Accessed 30 Nov 2019.

18. De Vet $\mathrm{H}$, Terwee C, Mokkink L, Knol D. Measurement in medicine, a practical guide: Cambridge University press; 2011.

19. Qin S, Nelson L, McLeod L, Eremenco S, Coons SJ. Assessing test-retest reliability of patient-reported outcome measures using intraclass correlation coefficients: recommendations for selecting and documenting the analytical formula. Qual Life Res. 2019;28(4):1029-33.

20. Koo TK, Li MY. A guideline of selecting and reporting Intraclass correlation coefficients for reliability research. J Chiropr Med. 2016;15(2):155-63.

21. Bland JM, Altman DG. Statistical methods for assessing agreement between two methods of clinical measurement. Lancet. 1986;1 (8476):307-10.

22. de Vet HC, Terwee CB, Knol DL, Bouter LM. When to use agreement versus reliability measures. J Clin Epidemiol. 2006;59(10):1033-9.

23. McHorney CA, Tarlov AR. Individual-patient monitoring in clinical practice: are available health status surveys adequate? Qual Life Res. 1995;4(4):293-307.

24. Cohen J. Statistical power analysis for the behavioral. 2nd ed. Hillsdale: Lawrence Erlbaum Associates; 1988.

25. Fountoulakis KN, Papadopoulou M, Kleanthous S, Papadopoulou A, Bizeli V, Nimatoudis I, et al. Reliability and psychometric properties of the Greek translation of the State-Trait Anxiety Inventory form Y: preliminary data. Ann Gen Psychiatry. 2006;5:2-859X-5-2

26. Iwata N, Mishima N, Shimizu T, Mizoue T, Fukuhara M, Hidano T, et al. The Japanese adaptation of the STAI form $Y$ in Japanese working adults--the presence or absence of anxiety. Ind Health. 1998;36(1):8-13.

27. Ma WF, Liu YC, Chen YF, Lane HY, Lai TJ, Huang LC. Evaluation of psychometric properties of the Chinese mandarin version state-trait anxiety inventory $Y$ form in Taiwanese outpatients with anxiety disorders. J Psychiatr Ment Health Nurs. 2013;20(6):499-507.

28. Quek KF, Low WY, Razack AH, Loh CS, Chua CB. Reliability and validity of the Spielberger state-trait anxiety inventory (STAl) among urological patients: a Malaysian study. Med J Malaysia. 2004;59(2):258-67.

\section{Publisher's Note}

Springer Nature remains neutral with regard to jurisdictional claims in published maps and institutional affiliations.

Ready to submit your research? Choose BMC and benefit from:

- fast, convenient online submission

- thorough peer review by experienced researchers in your field

- rapid publication on acceptance

- support for research data, including large and complex data types

- gold Open Access which fosters wider collaboration and increased citations

- maximum visibility for your research: over $100 \mathrm{M}$ website views per year

At $\mathrm{BMC}$, research is always in progress.

Learn more biomedcentral.com/submissions 